\title{
O Lebenswelt como fundamento da psicopatologia fenomenológica de Arthur Tatossian
}

Virginia Moreira1

Lucas Bloc ${ }^{2}$

Resumo: Este artigo tem como objetivo apresentar a psicopatologia fenomenológica de Arthur Tatossian como uma psicopatologia do Lebenswelt ("mundo da vida" ou "mundo vivido"). O conceito de Lebenswelt foi proposto por Husserl no âmbito da filosofia, tendo sido mais desenvolvido na última fase de seu pensamento. Na psicopatologia fenomenológica os conceitos filosóficos servem de inspiração para a discussão e construção da fenomenologia clínica. Nesta tradição, Arthur Tatossian realiza uma espécie de síntese de seus predecessores e propõe um modelo de psicopatologia que se edifica na compreensão do Lebenswelt.

Palavras-chave: psicopatologia fenomenológica, fenomenologia clínica, Arthur Tatossian, Lebenswelt.

\section{The Lebenswelt as foundation of Arthur Tatossian's phenomenological psychopatology}

\begin{abstract}
This article aims at presenting Arthur Tatossian's phenomenological psychopathology as a Lebenswelt's psychopathology (life's world or lived world). The Lebenswelt's concept was proposed by Husserl in the philosophy realm, having been more developed the last phase of his thouhgt. In the phenomenological psychopathology realm, philosophical concepts become the inspiration for the discussion and construction of clinical phenomenology. In
\end{abstract}

\footnotetext{
${ }^{1}$ Psicoterapeuta, Doutora em Psicologia Clínica pela Pontifícia Universidade Católica de São Paulo e Pós-Doutora em Antropologia Médica pela Harvard University, como pesquisadora Fulbright. É Professora Titular da Universidade de Fortaleza, Brasil, onde coordena o APHETO - Laboratório de Psicopatologia e Psicoterapia Humanista Fenomenológica. É Supervisora Clínica credenciada pela Sociedad Chilena de Psicológia Clínica, membro da World Association of Person Centered and Experiential Psychoterapies, membro da Associação Universitária de Pesquisa em Psicopatologia Fundamental. E-mail: virginiamoreira@unifor.br; virginia_moreira@fulbrightmail.org

${ }^{2}$ Psicoterapeuta, psicólogo e mestre em Psicologia pela Universidade de Fortaleza. Doutorando em Psicopatologia e Psicanálise na Université Denis Diderot - Paris VII e bolsista CAPES (Proc. 0998/14-1). É professor na Universidade de Fortaleza e membro do APHETO - Laboratório de Psicopatologia e Psicoterapia Humanista- Fenomenológica Crítica. E-mail: lucasbloc@yahoo.com.br.
} 
this tradition, Arthur Tatossian produces some sort of synthesis of his predecessors and proposes a model for psychopathology which is constructed from the Lebenswelt' comprehension.

Keywords: phenomenological psychopathology, clinical phenomenology, Arthur Tatossian, Lebenswelt.

\section{Introdução}

No início do século passado surge a psicopatologia fenomenológica com Binswanger, Minkowski e Von Gebsattel, seguidos de outros autores da tradição da psicopatologia fenomenológica. A aproximação entre a Fenomenologia e a Psiquiatria tornou possível este desenvolvimento, sedimentado sob a influência, às vezes acessória, e em outros momentos como referência direta (Tatossian, 1979/2006) dos principais autores da fenomenologia filosófica como Husserl, Heidegger e Merleau-Ponty.

Em um período mais recente, e realizando uma espécie de síntese do pensamento de seus predecessores, encontramos a proposta da psicopatologia fenomenológica de Arthur Tatossian (1929-1995), que caminha na direção de uma fenomenologia eminentemente existencial, que se sustenta sobre o conceito de Lebenswelt. Este conceito tem a capacidade de incorporar a existência, que é o aspecto que "interessa à psicopatologia fenomenológica em sua referência simultânea a Husserl e Heidegger" (Tatossian, 1979/2006, p. 87) e se configura como o eixo da fenomenologia existencial de Merleau-Ponty, ainda que existam diferenças.

No âmbito da Filosofia, o conceito de Lebenswelt - "mundo da vida" ou "mundo vivido" - foi proposto por Husserl e trabalhado ao longo de sua obra, sendo mais amplamente desenvolvido em sua última fase, no livro Die Krisis der euroäishen Wissenschaften und die transzentale Phänomenologie: Eine Einleitung in di phänomenologische Philosophie ${ }^{3}$. O Lebenswelt é o mundo vivido pré-reflexivo,

\footnotetext{
${ }^{3}$ A partir deste momento, chamaremos esta obra de Krisis, como usualmente é chamada.
} 
antes de ser pensado, o que já está lá, para aquém de qualquer pensamento idealista ou dualista. Neste sentido, no Lebenswelt não existe uma cisão entre exterior e interior, individual e social, consciente e inconsciente e assim por diante. O Lebenswelt é simultaneamente sujeito e objeto, se dá no mundo, no entrelaçamento entre o universal e o singular.

Como um constante vai-e-vem, em termos de inspiração, entre Husserl e Heidegger (Azorin, Naudin \& Pringuey, 2002), a obra de Tatossian se volta para o Lebenswelt que, ainda que seja um conceito desenvolvido mais amplamente pelo último Husserl, aquele do Krisis e do Expérience et Jugement (1939), e amplamente enfatizado por Merleau-Ponty como eixo de seu pensamento, permite uma aproximação também com a obra heideggeriana, sobretudo, na tentativa permanente de realizar uma analítica do ser-no-mundo em sua cotidianidade, mesmo que Heidegger, ele mesmo, não tenha se utilizado do conceito de Lebenswelt.

Segundo Cabestan e Dastur (2011), Tatossian compreende que uma assimilação da antropologia na fenomenologia exige "nada menos que a absorção do pensamento de Heidegger naquele do Husserl tardio, a saber, a problemática do Lebenswelt" (Cabestan \& Dastur, 2011, p. 156). Trata-se da abordagem antropológica da psiquiatria que, para Tatossian, representa a tentativa de ir além do dualismo cartesiano entre psique e soma, ideia que já estava na origem da psicopatologia fenomenológica nos anos 1920 (Cabestan \& Dastur, 2011). A fenomenologia clínica de Arthur Tatossian reconhece a dupla importância dos pensamentos de Husserl e Heidegger, além dos pensamentos filosóficos representantes da fenomenologia existencial, na psicopatologia fenomenológica. Este artigo tem como objetivo apresentar a psicopatologia fenomenológica de Arthur Tatossian como uma psicopatologia do Lebenswelt. 


\section{1) O conceito de Lebenswelt na fenomenologia filosófica de Husserl e sua} contribuição para a psicopatologia fenomenológica

O conceito de Lebenswelt, cunhado por Husserl, faz referência direta ou indiretamente a outros grandes representantes da fenomenologia como Heidegger, que nunca se utilizou deste conceito, visto que sua preocupação era o Dasein, e Merleau-Ponty que, ao contrário, teve no conceito de Lebesnwelt o fio condutor de seu pensamento, dando continuidade diretamente à filosofia Husserl do Krisis, radicalizando seu caráter existencial. Entendemos esta referência justamente pelo caráter existencial que o pensamento dos sucessores de Husserl assume. Além disso, ao longo da obra de Husserl este conceito é formulado de diferentes formas e com diferentes objetivos. Neste artigo, apresentamos o conceito de Lebenswelt, como exposto principalmente no Krisis, no que tange a sua contribuição para a constituição e para o desenvolvimento da psicopatologia fenomenológica de Arthur Tatossian, visto que, independentemente do questionamento de onde começa e termina a fenomenologia, para o psiquiatra francês, seu centro de gravidade se encontra na obra de Husserl (Tatossian, 1996). Esta concepção não desvaloriza nem a obra de Heidegger nem a de Merleau-Ponty, mas as integra, principalmente se considerarmos que ambos partiram de Husserl (Moreira, 2010), mesmo que de uma forma eminentemente crítica. Praticamente todas as filosofias da existência contemporâneas se originam direta ou indiretamente das reflexões husserlianas, gerando implicações em várias áreas do conhecimento como a Psicologia, a Psiquiatria e a própria Filosofia (Holanda \& Freitas, 2011).

O conceito de mundo aos poucos foi ganhando espaço na obra de Husserl, eclodindo no direcionamento do seu pensamento no sentido do mundo vivido (Lebenswelt) como "terreno comum do viver humano" (Husserl, 1954/1976, p. 176). Efetivamente, o termo Lebenswelt foi utilizado por Husserl pela primeira vez em seus manuscritos em meados de 1917, muito embora não tenha dado um extensivo tratamento ao significado fenomenológico do termo (Zelic, 2007). O conceito de mundo, de forma geral, é discutido ao longo de toda 
a obra de Husserl, mas a ideia de mundo da vida - Lebenswelt - se efetiva e se sistematiza solidamente no Krisis.

Segundo Husserl (1954/1976, p. 177), este mundo vivido designa “o mundo em que vivemos intuitivamente, com suas realidades, do modo como se dão, primeiramente na experiência simples e depois também nos modos em que sua validade se torna oscilante (oscilante entre ser e aparência, etc.)". Tratase de um mundo vivido, em contraposição ao mundo da ciência que se dá posteriormente, que busca atingir justamente o pré-científico, o pré-reflexivo na experiência de um mundo para todos.

Depraz (2008, p. 119) define mundo da vida como "índice único e solo de nossa inscrição prática, sensível e comunitária enquanto sujeitos encarnados" e afirma que esta noção tem origem em uma "necessidade vital de reenraizar as abstrações científicas em seu ambiente imediato e prático". O mundo vivido é pensado aqui como solo, terreno da nossa existência e elemento fundamental para se compreender a experiência vivida. No Krisis, Husserl (1954/1976) estende seu pensamento para uma análise do mundo vivido em sua estreita ligação e enraizamento na experiência humana.

David Carr (1987), um dos mais importantes comentadores de Husserl, reconhece três elementos-chave no conceito de mundo-da-vida. O primeiro diz respeito ao seu caráter de ser já-dado de forma anterior a qualquer ciência. $\mathrm{O}$ segundo relaciona-se ao fato do mundo-da-vida ser descrito como público, constituído de modo intersubjetivo, ou seja, ele já se dá intersubjetivamente. E o terceiro refere-se à atribuição de elementos culturais ao mundo-da-vida. $\mathrm{O}$ caráter eminentemente intersubjetivo do mundo vivido, apontado por Carr na obra de Husserl, também é destacado por Tatossian.

Para Husserl (1954/1976, p. 185), devemos direcionar a atenção para o fato que "nós não estamos isolados no fluxo contínuo de nossa percepção de mundo, e que nós temos, ao contrário, nele, ao mesmo tempo, uma conexão com os outros homens", há uma "unidade intersubjetiva na diversidade das validações" (1954/1976, p. 186). Os homens são co-sujeitos de suas próprias experiências que estão sempre em movimento em um horizonte infinitamente 
aberto. Além de ter sido o primeiro a falar de uma Psicologia Fenomenológica, Husserl incorporou esta concepção em seu projeto fenomenológico na busca de um fundamento para a subjetividade (Goto, 2008). Então, com o advento de uma concepção de psicologia fenomenológica via Husserl, a subjetividade foi resgatada como uma fonte originária da vida e deu-se destaque também a sua correlação com o Lebenswelt, terreno fértil para a psicologia clínica e para a psiquiatria, no desenvolvimento de uma clínica do Lebenswelt. (Moreira, 2010; Tatossian \& Moreira, 2012).

Tatossian e Azorin (1984, p. 529) consideram que “os desenvolvimentos mais recentes da psicopatologia fenomenológica são marcados por uma inflexão ou, antes, uma re-inflexão na direção da obra de Husserl e, principalmente, do Husserl tardio, aquele do mundo-da-vida (Lebenswelt) e da intersubjetividade". Este é um movimento que pode ser identificado, principalmente, nos livros Mélancolie et Manie (1960/2005) de Binswanger, La Melancolía (1961/1976) de Tellenbach e no livro de Blankenburg La perte de l'évidence naturelle; Une contribuition à la psychopathologie des schizophrénies pauci-smptomatiques (1971/1991).

No Krisis, Husserl tem o mérito de apresentar uma nova via para a Psicologia, diferente da Psicologia científica tradicional da época, que se restringia à observação de comportamentos objetivos, passando a olhar para a subjetividade humana. Com este passo, Husserl sedimenta um solo fecundo para o desenvolvimento posterior das fenomenologias existenciais que subsidiam vários pensamentos psiquiátricos e psicológicos (Moreira, 2010), tendo o próprio Tatossian como um representante.

A clínica fenomenológica na psicologia e na psiquiatria pode encontrar nos pensamentos de Husserl e Merleau-Ponty, de diferentes formas, um grande potencial a ser usufruído (Moreira, 2010) via conceito de Lebenswelt. Este potencial, amplamente aproveitado por Tatossian, serve de inspiração nos diferentes diálogos e construções que constituem o fundamento epistemológico de seu pensamento. Trata-se de uma psicopatologia de inspiração fenomenológica cujo ponto central é utilizar este potencial no sentido da 
compreensão do vivido do paciente e na construção de uma clínica fenomenológica do Lebenswelt (Tatossian \& Moreira, 2012).

\section{2) Uma clínica fenomenológica do Lebenswelt}

Tendo as fenomenologias filosóficas do Husserl tardio e de Heidegger como inspiração, Tatossian solidifica epistemologicamente sua prática clínica com a possibilidade de aliar esta fenomenologia com a psicopatologia fenomenológica e desenvolver o que estamos chamando de uma clínica fenomenológica do Lebenswelt (Tatossian \& Moreira, 2012). Clínica e psicopatologia não são nomeações da prática e da teoria, pois são aqui indissociáveis em sua mútua constituição (Bloc, 2012; Moreira \& Bloc, 2012).

Precisar como a fenomenologia filosófica influencia, ou mesmo dá condições, para o desenvolvimento da psicopatologia e da clínica fenomenológica de Tatossian não é uma tarefa fácil e encontramos na sua própria teoria uma justificativa. Em A Fenomenologia das Psicoses (2006), Tatossian faz um percurso histórico e crítico das psicoses na psicopatologia e na psiquiatria, iniciando justamente com a discussão acerca da relação entre a fenomenologia e a psiquiatria. Apesar de iniciar com um caminho filosófico, Tatossian afirma que o clínico, ainda que se atenha a discussões filosóficas, para atingir a experiência propriamente fenomenológica "deve preferir obrigatoriamente o comércio direto com o que está em questão: a loucura e o louco" (Tatossian, 1979/2006, p. 29). As noções filosóficas são importantes, mas devem ser precisadas a partir das necessidades que se impõem no e pelo curso da experiência e não ao contrário. Trata-se de uma maneira de trabalhar em fluxo, que Tatossian $(1979 / 2006,1980,1986,1997)$ defende ao longo de suas obras a partir da fenomenologia.

Tatossian considera um erro e, até mesmo, um contrassenso, a mera aplicação da fenomenologia, como doutrina filosófica, na psicopatologia: "A psicopatologia fenomenológica se inspira da fenomenologia filosófica, uma vez que foi fundada por Husserl e retomada por Heidegger na Alemanha, como por Merleau-Ponty e Sartre na França" (Tatossian \& Azorin, 1984, p. 528). Ou seja, 
Tatossian posiciona a fenomenologia filosófica a partir de uma demanda que surge com a experiência do outro e que serve de inspiração à psicopatologia, retirando a possibilidade de uma via estática de compreender a experiência do paciente. As diferentes noções filosóficas aparecem ao longo da experiência fenomenológica, e não como uma reflexão fenomenológica sobre a experiência, o que significa um posicionamento de não fechamento àquilo que de mais importante a fenomenologia considera: a experiência.

A clínica fenomenológica, para Tatossian e Giudicelli (1973), se compõe duplamente pelo método fenomenológico husserliano e pela analítica existencial heideggeriana, em uma dualidade considerada necessária. A partir do Husserl tardio, a fenomenologia vai além de um método, possibilitando o desenvolvimento de uma antropologia autônoma que consegue absorver o pensamento de Heidegger, pelo menos aquele presente no Ser e Tempo, e permite uma premunição contra aquilo que se considera a maior dificuldade da psiquiatria e da psicopatologia fenomenológica: o risco de recair no psicologismo (Tatossian e Giudicelli, 1973). Ao mesmo tempo, com Heidegger, é possível se voltar para aspectos ontológicos, existenciais constituintes do Dasein, que Tatossian considera fundamentais, como a temporalidade, a espacialidade, o ser-com e a noção de cuidado, presentes no desenvolvimento da obra de Tatossian $(1993 / 1997,1996,1997)$ e que demonstram a influência da ontologia de Heidegger.

A analítica heideggeriana da Presença busca compreender o ser-nomundo em sua cotidianidade, o que justificaria, para Tatossian (1979/2006), um deslocamento do interesse do psicopatólogo da fenomenologia de Husserl à analítica de Heidegger. No entanto, ele considera que evidenciar a antropologia no Ser e Tempo seria um equívoco, já que o próprio Heidegger não demonstrava interesse nisso e isto levaria ao risco de sucumbir a uma imobilização fechada e limitante da liberdade da experiência fenomenológica. É com este questionamento que Tatossian atribui a reorientação da fenomenologia psiquiátrica de sua época, impulsionada, sobretudo, por Binswanger (1960/2005; 1965/2010), em direção ao Husserl tardio, que se centra sobre as 
noções de egologia, de constituição genética e de mundo vivido (Tatossian, 1979/2006).

O interesse de Tatossian se direciona, então, para a unidade estrutural das experiências possíveis. Não se trata mais de um conteúdo fechado, de considerar a experiência como algo acabado, mas compreender a experiência sempre como um ponto de partida e de chegada, um vivido em movimento. Em termos clínicos, não se trata de reviver uma experiência, mas de penetrar até o que ela é, atingindo o pré-predicativo e o pré-reflexivo a partir do qual se origina a experiência. Atingir este nível é chegar ao mundo da vida (Lebenswelt) husserliano (Tatossian \& Giudicelli, 1973).

Sempre inspirado pela tradição fenomenológica, Tatossian (1979/2006) considera que o Lebenswelt significa o direcionamento para uma realidade primária - o mundo das significações é, na forma em que se apresenta, sobretudo, o mundo dos indivíduos, a existência vivida em sua unicidade (Tatossian \& Moreira, 2012). É o lugar do homem, onde o indivíduo vive primariamente, tendo como essencial a sua familiaridade de um mundo que é "seu" e que, através da consciência, torna a experiência do Lebenswelt normal, excluindo tanto a particularidade extrema quanto a generalidade extrema da experiência. Há sempre um mundo cotidiano tido como realidade, mas uma realidade que também é social e constitui um sentido comum, qualquer que seja o conteúdo.

Para Tatossian (1979/2006, p. 88), o Lebenswelt é o mundo correlativo da atitude natural no nível pré-intencional, em uma experiência que pode variar como conteúdo, como Lebenswelten, mas "a forma do Lebenswelt é única" , pois há sempre um “sentido comum” porque “'meu' mundo é sempre assim 'nosso' mundo, um mundo intersubjetivo, um mundo comum". É um mundo abaixo das construções do pensamento, anterior.

Tatossian (1979/2006) destaca um esforço propriamente fenomenológico e um duplo esforço da psicopatologia ao visar duas experiências do Lebenswelt do doente. De um lado, a experiência pré-teórica e pré-objetiva que se dá diante do sujeito e, de outro lado, o questionamento de como se constitui o Lebenswelt 
próprio, particular, que se imprime sobre a experiência, sobre o vivido e suas formas de se apresentar. Busca-se aí, em um objetivo comum, compreender como o paciente constitui a Si e ao Mundo, considerando sempre a relação com o corpo e o caminho que compõe a evidência natural, sendo esta, usualmente fracassada no doente.

Esta dupla tarefa Tatossian (1979/2006) considera difícil, e justifica que, no primeiro caso, não se trata de liberar sua própria experiência fenomenológica dos momentos objetivos e subjetivos que se misturam na experiência do Lebenswelt; no segundo, é necessário atingir aquela do doente através de suas apresentações de si, não se colocando no lugar dele e em sua pele e sua alma por uma intropatia (Einfühlung) desusada, mas pelo que Binswanger descreveu como uma comunicação hermenêutica ou "comunicação redobrada" (Tatossian, 1979/2006, p. 89).

A busca pela experiência fenomenológica, em sua dupla tarefa, se mostra difícil pela inseparabilidade entre experiência objetiva e subjetiva, e na dificuldade em ter como central o fenômeno que se mostra a partir da experiência do outro. Segue-se aqui um caminho constitutivo, de uma fenomenologia egológica que questiona a constituição de si e do mundo e, ao mesmo tempo, parte sempre de uma experiência que se mostra clinicamente. $\mathrm{O}$ Lebenswelt para Tatossian (1979/2006, p. 207) “existe como mundo concreto e cotidiano, que, ele é sempre individual, é sempre 'meu' mundo, sendo também totalmente 'nosso' mundo porque impregnado de historicidade e intersubjetividade".

A consideração e a relevância da cotidianidade da experiência por Tatossian têm origem também no conceito de Lebenswelt. A dificuldade parece ser a de sair de uma compreensão dicotômica e, muitas vezes, natural, para uma experiência ambígua, aquela que compreende a constituição de uma subjetividade que não é puramente individual, pois faz parte de um mundo que é ao mesmo tempo constituído pelo sujeito e pelos outros, em seu caráter eminentemente intersubjetivo. O mundo não é meu ou nosso, é meu e nosso diante da historicidade e intersubjetividade que nos constitui. Trata-se de uma 
via para compreender o significado do Lebenswelt na experiência que se desdobra no entrelaçamento de um mundo individual e, ao mesmo tempo, comum.

Um quadro psicopatológico passa, assim, a ser reconhecido a partir de um apriori comum que me permite reconhecê-lo como tal. Ou seja, só reconheço um paciente com um quadro depressivo a partir de uma concepção prévia do que seria a depressão, algo possibilitado por uma atitude natural construída no Lebenswelt. Por outro lado, tal atitude só me é possível a partir também de uma experiência que se mostra, que se apresenta clinicamente, e permite, a partir do contato com o outro, o reconhecimento de um modo de funcionar que se aproxima do vivido depressivo. Trata-se de uma tentativa de reunir na busca da compreensão da experiência fenomenológica a teoria e a prática como aliados e elementos indissociáveis.

Ainda que se fale de uma priorização do fenômeno como modo de ser global do sujeito, não se trata apenas de algo particular, existem elementos comuns que permitem reconhecer tal modo de ser. É neste sentido que Tatossian (1979/2006, 1994) fala, por exemplo, de um diagnóstico da depressividade ou da esquizofrenicidade, e não da depressão ou da esquizofrenia. Há a incorporação de um movimento que se dá no Lebenswelt, de uma percepção que se dá com e no sintoma, possibilitada empiricamente e aprioristicamente. Tal aspecto liga indissoluvelmente a clínica, reconhecida e desenvolvida através do contato com o paciente, e psicopatologia, como área que visa aprioristicamente compreender os diferentes modos de funcionamento, servindo de subsídio para a própria clínica. Há aqui sempre a necessidade de sair de uma atitude natural para uma atitude fenomenológica que permita o desvelamento do fenômeno; eis a função e a proposta de uma psicopatologia que se assume fenomenológica. 


\section{Considerações finais}

O desenvolvimento da obra de Arthur Tatossian segue na direção de uma psicopatologia e de uma clínica fenomenológica do Lebenswelt (Tatossian \& Moreira, 2012). Trata-se de partir para a origem, para a constituição do vivido psicopatológico, mas sem desconsiderar aquilo que o constitui, bem como o fluxo da experiência, que não para e que deve ser visada pelo clínico. Esta discussão, que tem como origem a utilização do conceito de Lebenswelt por Tatossian, ecoa também no lugar que a subjetividade, enquanto intersubjetividade, assume e pode assumir a partir desta concepção, projeto também iniciado por Husserl.

O conceito de Lebenswelt marca o pensamento de Tatossian por acentuar o trabalho clínico com a cotidianidade do homem em seu lugar, em seu mundo que é também nosso mundo, É a busca da compreensão do Lebenswelt que faz com que Tatossian desenvolva sua psicopatologia como um trabalho ambíguo, na interseção do singular e do universal, em uma experiência que se dá sempre no mundo.

Embora neste artigo tenhamos priorizado a discussão do conceito de Lebenswelt na filosofia de Husserl, seu criador, é importante ressaltarmos que Heidegger, de forma mais direta com sua hermenêutica do Dasein, e MerleauPonty, de uma forma mais velada com sua fenomenologia da ambiguidade que caracteriza o Lebenswelt, também se apresentam como referencias fundamentais para a constituição da psicopatologia do Lebenswelt de Tatossian. Na busca da compreensão do Lebenswelt trabalha-se em um nível pré-intencional que permite o aparecimento de aspectos como a intersubjetividade e a significação enquanto mundo vivido pré-reflexivo e, portanto, ambíguo, ou para aquém do pensamento dualista; de maneira que o trabalho clínico, também ambíguo, gira em torno de uma psicopatologia fenomenológica da clínica e para a clínica. 


\section{Referências bibliográficas}

Azorin, J-M, Naudin, J. \& Pringuey, D. (2002) Préface. In A. Tatossian, La Phénoménologie des Psychoses (3e éd., pp. 9-12). Paris: Collection Phéno, Le Cercle Hermeneutique.

Binswanger, L. (2005) Melancolie et Manie. Paris: Presses Universitaires de France. (Originalmente publicado em 1960).

Binswanger, L. (2010) Délire. Grenoble: Jérôme Millon. (Publicado originalmente em 1965).

Blankenburg, W. (1991) La perte de l'évidence naturelle. Une contribuition à la psychopathologie des schizophrénies pauci-symptomatiques. Paris: Presses Universitaires. (Originalmente publicado em 1971).

Bloc, L. G. (2012) Introdução à psicopatologia fenomenológica de Arthur Tatossian. Disssertação de mestrado não-publicada, Programa de Pós-Graduação em Psicologia, Universidade de Fortaleza.

Cabestan, P. \& Dastur, F. (2011) Dasiensanalyse: Phénoménologie et psychiatrie. Paris: Librairie Philosophique J. VRIN.

Carr, D. (1987) Interpreting Husserl. Critical and Comparative Studies. Dordrecht: Martinus Nijhoff Publishers.

Depraz, N. (2008) Compreender Husserl. (Fábio dos Santos, trad., $2^{\mathrm{a}}$ ed.). Petrópolis, Rj: Vozes.

Goto, T. A. (2008) Introdução à psicologia fenomenológica: a nova psicologia de Edmund Husserl. São Paulo: Paulus.

Holanda, A. \& Freitas, J. L. (2011) Fenomenologia e Psicologia: Vinculações. Em A. J. Peixoto (org.), Fenomenologia: diálogos possíveis. Campinas, SP: Ed. Alínea; Goiânia, GO: Editora da PUC de Goiás.

Husserl, E. (1976) La crise des sciences européennes et la phénoménologie transcendantale. (G. Granel, trad.). Paris: Éditions Gallimard. (Originalmente publicada em 1954).

Moreira, V. (2010) Possíveis contribuições de Husserl e Heidegger para a clínica fenomenológica. Psicologia em Estudo, Maringá, 15(4), 723-731.

Moreira, V. \& Bloc, L. (2012) Clínica do Lebenswelt (mundo vivido): articulação e implicação entre teoria e prática. In: A. Tatossian e V. Moreira, Clínica do Lebenswelt (mundo vivido): Psicopatologia e Psicoterapia Fenomenológica (pp. 285-298). São Paulo: Editora Escuta. 
O Lebenswelt como fundamento da Psicopatologia Fenomenológica de Arthur Tatossian

Tatossian, A. (1980) Théorie et pratique en psychiatrie: symptôme et phénomène. Un point de vue phénoménologique. Actu. Psychiatr., 10, 59-63.

Tatossian, A. (1986) Pratique Psychiatrique et Phénoménologie. In P. Fédida e P. Gutton. Phénoménologie, Psychiatrie, Psychanalyse (p. 123-131). Paris: Echoscenturion.

Tatossian, A. (1994) La subjectivité. In : D. Widlöcher. Traité de Psychopathologie (pp. 253-318). Paris: Presses Universitaires de France.

Tatossian, A. (1996) Phénoménologie: une épistémologie pour le psychiatre. Confront. Psychiatr., 37, 177-195.

Tatossian, A. (1997). Pratique psychiatrique et phenomenologie. In A. Tatossian. Psychiatrie phénomenologique (p. 179-183). Paris: Acanthe. (Originalmente publicado em 1985).

Tatossian, A. (1997) L'experience du phénomène et le projet psychothérapique. In A. Tatossian. Psychiatrie phénomenologique (p. 215-223). Paris: Acanthe. (Originalmente publicado em 1993).

Tatossian, A. (2006) A fenomenologia das psicoses (J.C. Freire, trad. e V. Moreira, rev. Tec.). São Paulo: Escuta. (Originalmente publicado em 1979).

Tatossian, A. \& Azorin, J-M (1984) Phénoménologie. In A. Porot. Mannuel Alphabetique de Psychiatrie (p. 528-529). $6^{\mathrm{a}}$ ed. Paris: Presses Universitaires de France.

Tatossian, A. \& Giudicelli. (1973) De la phénoménologie de Jaspers au "retour a Husserl": l'anthropologie compréhensive de Zutt et Kulenkampff. Confrontations psychiatriques, 6, 127-161.

Tatossian, A. \& Moreira, V. (2012) Clínica do Lebenswelt (mundo vivido): Psicopatologia e Psicoterapia Fenomenológica. São Paulo: Editora Escuta.

Tellenbach, H. (1976) La melancolía. Visión histórica del problema: Endogenidad, tipologia, patogenia y clínica. Madrid: Ediciones Morata. (Originalmente publicado em 1961).

Zelic, T. (2007) On the Phenomenology of the Life-World. Synthesis Philosophica, $46,413-426$. 